\title{
BEHAVIOR IN AC POLARIZATION OF HIGH-SILICON CAST IRONS
}

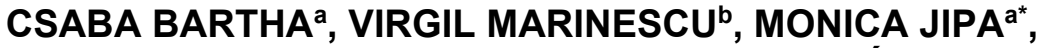 \\ BEATRICE-GABRIELA SBARCEA ${ }^{b}$, ATTILA TÓKOS ${ }^{a}$, \\ ALINA-RUXANDRA CARAMITU' ${ }^{\mathrm{b}}$, IOSIF LINGVAYa
}

\begin{abstract}
The behavior of high-silicon cast irons in AC polarization was studied in terms of elementary composition and morphological structure to find suitable materials for inert anodes used in various electrochemical processes with polarization in $A C$ or DC with superimposed AC signal. Experimentally, through optical emission spectrometry, XRD, and SEM-EDAX techniques, the investigated samples' morphology and composition were determined. The behavior in $\mathrm{AC}$ polarization at $J_{a c}$ current density between 1 and $300 \mathrm{~A} / \mathrm{m}^{2}$ was assessed through electrochemical and gravimetric methods. The results showed that the mass losses in AC polarization at $J_{a c}$ less than $10 \mathrm{~A} / \mathrm{m}^{2}$ are insignificant (below $8.5 \times 10^{-5} \mathrm{~g} / \mathrm{Ah}$ ), and at $J_{a c} 100 \mathrm{~A} / \mathrm{m}^{2}$, samples with a $\mathrm{Si}$ content higher than $8 \%$ were below $3.75 \times 10^{-4} \mathrm{~g} / \mathrm{Ah}$ (approx. 150x less than in the case of similar anodically polarized materials in DC). It was also noted that the main processes that occur in the AC polarization of silicone cast iron in aqueous media consist of the anodic oxidation of iron with the formation of iron oxide films and the anodic dissolution with the formation of soluble compounds of some metals from the composition of silicone cast irons ( $\mathrm{Mn}$, $\mathrm{Cr}, \mathrm{Cu}$, etc.). Furthermore, these anodic processes are coupled with the cathodic processes, which in natural environments consist most probably in reducing the dissolved oxygen.
\end{abstract}

Keywords: silicon cast iron, corrosion, AC polarization, mass loss, inert anodes

${ }^{a}$ Research-Development Institute for Environmental Protection Technologies and Equipment, Str. Parcului, Nr. 7, 420035, Bistrița, România

${ }^{b}$ National Institute for Research and Development in Electrical Engineering INCDIE ICPECA,313 Splaiul Unirii, RO-030138, Bucharest, Romania

*Corresponding author: monica.jipa@icpebn.ro 


\section{INTRODUCTION}

In the view of sustainable development, maintaining a clean environment and conserving natural resources is a priority issue [1-3]. In this background, the development and characterization of new materials, with functional characteristics suitable for various applications, ensuring sustainable exploitation without toxic waste at the end of their life span, are always current research topics [4].

The development of any chemical synthesis process is conditioned thermodynamically by the activation energy required for the process. Thermal control of chemical processes (ensuring the activation energy required to initiate and carry out the process through thermal transfer) has many disadvantages, compared to the electrochemical control (energy losses in the production chain, transport and transfer of thermal energy, high response time, and hysteresis of regulation/automation systems, complicated equipment/reactors with high material consumption). In the case of electrochemical syntheses, the process control is relatively simple by overvoltage $\eta$, respectively, by controlling the current density $J\left[\mathrm{~A} / \mathrm{m}^{2}\right]$, which crosses the surface of the electrodes- Taffel's law (1):

$$
\eta=a+b \ln j,
$$

where $a$ and $b$ are constants specific to the process/electrochemical system and depend on the temperature [5].

Development and advanced characterization (including electrochemical behavior) of materials suitable for the production of electrodes, which under specific operating conditions exhibits stability and adequate electrochemical behavior in anodic [6-12] or cathodic [13-16] polarization, limits the widespread application of the electrochemical technologies. A particular case is the applications of polarized electrodes in AC or DC superimposed with AC signal, such as grounding systems of electrical power systems [17], electrical and corrosion protection of underground pipelines interfered by induced AC stray currents $[18,19]$.

Recent studies show that the microorganisms' biochemical activity, including those in the activated sludge from wastewater treatments, can be stimulated by exposing the biomass to an extremely low-frequency electric field (ELF) [20-28].

High-silicon cast irons present high stability under anodic polarization conditions (low dissolution rate) $[29,30]$ and are used frequently in the production of anodes for cathodic protection systems of underground or underwater metallic structures [31, 32]. 
Therefore, for the development of suitable materials used in various applications, such as long-lasting (lifetime over 100 years) earthing plats for electrical grids or passive electrodes for bioreactors with electromagnetic field stimulation, the paper aims to study the behavior of high-silicon cast irons in AC polarization.

\section{RESULTS AND DISCUSSION}

Table 1 covers the chemical composition, determined experimentally, and the assigned code for the high-silicon cast iron samples.

Table 1 shows that the samples obtained are iron alloys with high silicon content (between 2.98 and 17.77\%- depending on the dosed metallurgical silicon, and a series of elements from the used raw materials (steel scraps and metallurgical silicon).

Table 1. Composition and coding of high-silicon cast iron samples

\begin{tabular}{|c|c|c|c|c|c|c|c|c|c|c|}
\hline \multirow{2}{*}{$\begin{array}{c}\text { Sample } \\
\text { code }\end{array}$} & \multicolumn{10}{|c|}{ Content [\%] } \\
\hline & $\mathbf{S i}$ & $\mathrm{Fe}$ & C & Mn & $\mathrm{Cr}$ & Mo & $\mathrm{Cu}$ & S & $\mathbf{P}$ & Others \\
\hline $\mathrm{Si3}$ & 2.98 & 90.1 & 1.06 & 0.33 & 0.23 & 0.03 & 0.43 & 0.04 & 0.05 & \multirow{5}{*}{ 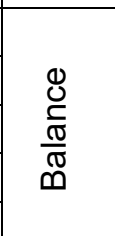 } \\
\hline Si8 & 8.12 & 84.9 & 1.14 & 0.55 & 0.49 & 0.06 & 0.49 & 0.02 & 0.04 & \\
\hline Si11 & 11.21 & 86.3 & 0.85 & 0.64 & 0.51 & 0.09 & 0.16 & 0.03 & 0.03 & \\
\hline Si14 & 14.1 & 81.1 & 1.05 & 0.98 & 0.83 & 0.14 & 0.56 & 0.06 & 0.07 & \\
\hline Si18 & 17.77 & 79.3 & 1.03 & 0.49 & 0.21 & $0 \Omega 4$ & 091 & 0,4 & 0.06 & \\
\hline
\end{tabular}

Figure 1 illustrates the XRD diffractogram recorded for the Si3 sample.

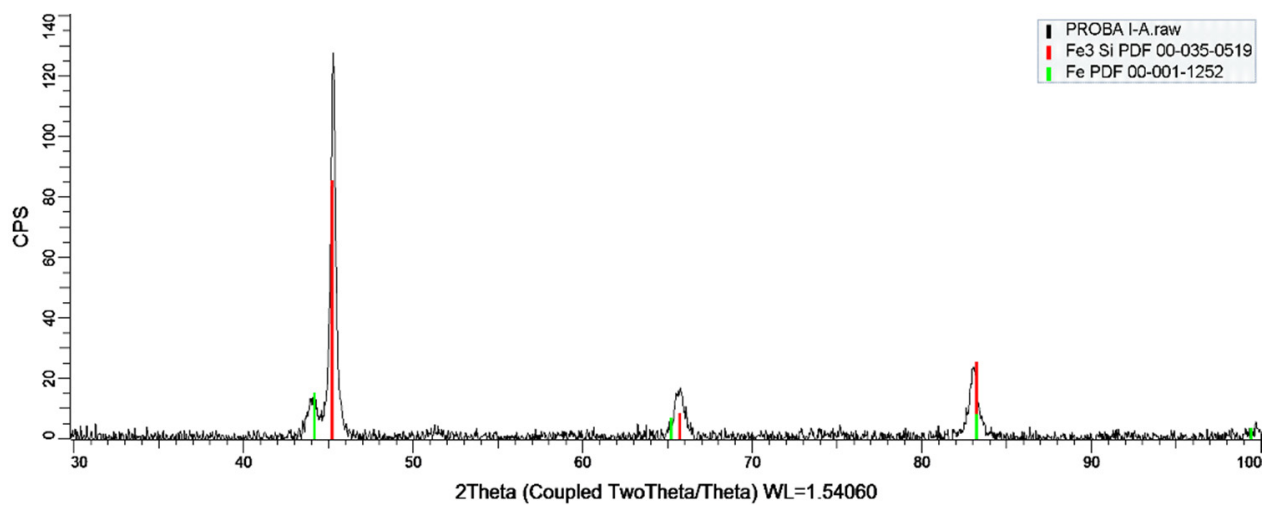

Figure 1. XRD diffractogram recorded on sample Si3. 
$\mathrm{Fe}_{3} \mathrm{Si}$ and $\mathrm{Fe}$.

Figure 1 show that the Si3 sample contains two crystalline phases

The XRD diffractograms recorded on the Si8, Si11, Si14, and Si18 samples were similar and presented in Figure 2.

Figure 2 reveals that the investigated samples with $\mathrm{Si}$ content between 8 and $18 \%$ contain a single crystalline phase, respectively $\mathrm{Fe}_{3} \mathrm{Si}$ (cementite), result in compliance with those reported in [33].

Figure 3 illustrates the results recorded on the Si8 sample regarding the evolutions of the open circuit potentials $\left(E_{O C P}=E_{c o r r}\right.$ at $\left.J_{a c}=0\right)$ and the polarization potential $E_{A C}$ in $50 \mathrm{~Hz} \mathrm{AC}$, at $J_{a c}$ current densities between 1 and $300 \mathrm{~A} / \mathrm{m}^{2}$ in $0.1 \mathrm{M} \mathrm{KCl}$ solution.

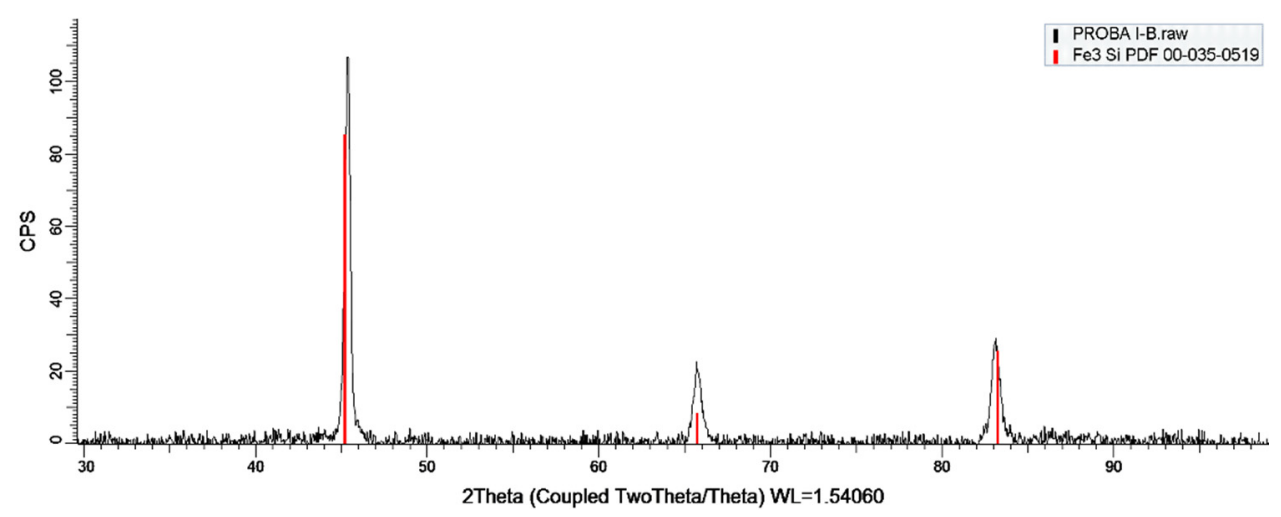

Figure 2. XRD diffractogram recorded on samples Si8, Si11, Si14, and Si18

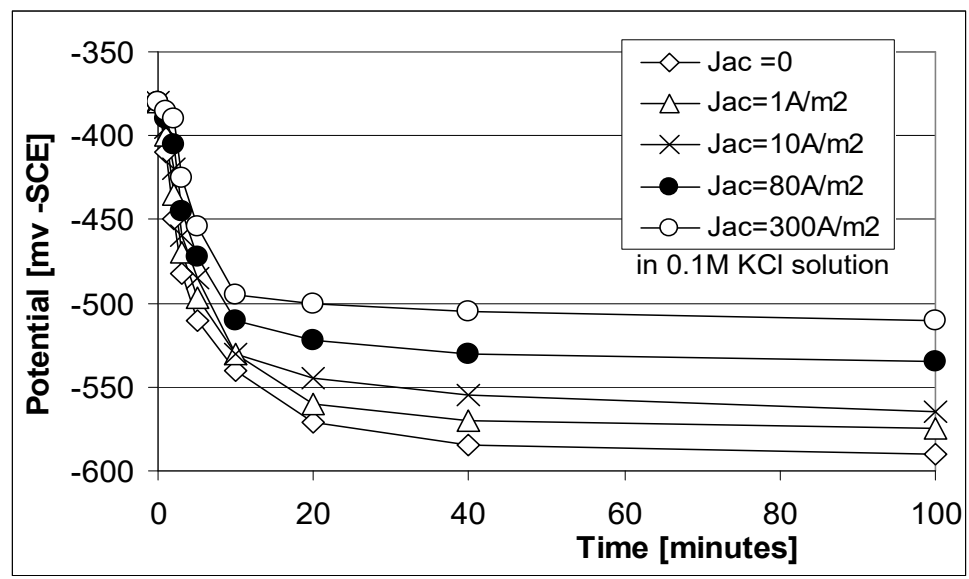

Figure 3. Time evolutions of $E_{\text {corr }}$ and $E_{A C}$ recorded on the Si8 sample. 
Figure 3 analysis shows that at the immersion of the sample in $0.1 \mathrm{M}$ $\mathrm{KCl}$ solution, the open circuit potential of the metal display a continuous migration trend towards more electronegative values After an initiation/ stabilization time (approx. 20 minutes, in which the variations are significant) it tends asymptotically to the value of $-590 \mathrm{mV}$, expressing the mixed $E_{\text {corr }}$ corrosion potential of the sample. This value is determined by the electrolytic system's nature (given primarily by the metal's electronegativity, the electrolyte's composition, temperature, and dissolved oxygen/partial oxygen pressure). Further, following the sample polarization in $A C$, the electrode potential migration trend towards more electropositive values is more pronounced, and the value at which the EAC potential stabilizes is determined by the density of the Jac polarization current.

Annotating with $\Delta_{E}$, the value wherewith the mixed corrosion potential migrates to more electropositive values, under the influence of the $E_{A C}$ polarization current, we have (2):

$$
\Delta_{E}=E_{A C}-E_{c o r r}=f\left(J_{a c}\right),
$$

wherein $\mathrm{f}\left(\mathrm{J}_{\mathrm{ac}}\right)$ expresses the variation function of the potential under polarization in alternating current.

The evolution of the potential under the action of the polarization current in AC can be explained by Figure 4, which graphically illustrates the response of a metal/electrolyte electrochemical system, characterized by the polarization curve $i=f(E)$ to equilibrium disturbance by applying in $E_{\text {corr }}$ of a sinusoidal polarization voltages in AC having the period $T$.

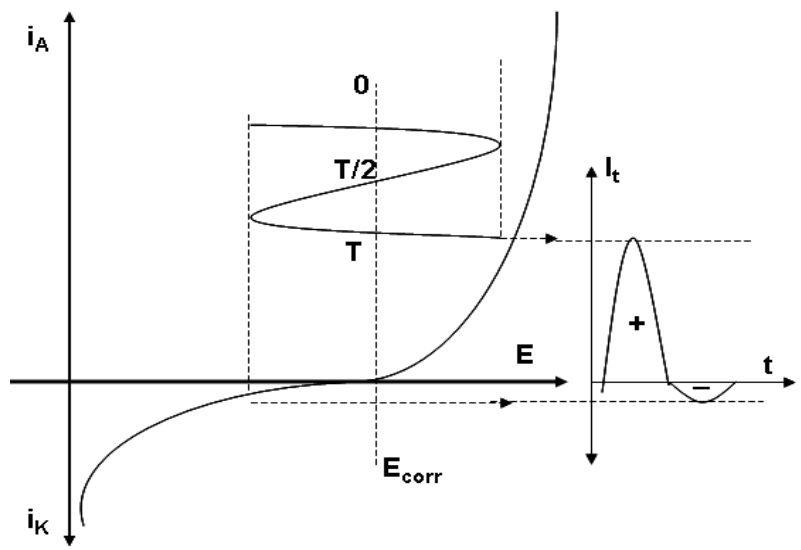

Figure 4. The metal/electrolyte system response at polarization through an AC disturbing signal overlapped in $\mathrm{E}_{\mathrm{corr}} ; i_{A}$ - global anodic current; $i_{K}$ - global cathodic current; $E_{\text {corr }}$ mixed corrosion potential; $T$ - duration of one period of disturbing sinusoidal signal; $l_{t}$ - evolution of the AC polarization current 
Figure 4 shows that the electrochemical system responds to polarization in sinusoidal $\mathrm{AC}$ with a distorted alternating current, in which the share of the anodic half-period (+) is higher than that of the cathode halfperiod (-), which globally leads to an anodic polarization of the system and implicitly to the migration with $\Delta_{E}$ towards more electropositive values of the electrode potential.

Thus, considering that the value of $\Delta_{E}$ indicates the effect of AC polarization on the metallic material's electrochemical stability, it can be considered a parameter in evaluating the material's passivity to polarization in AC. Time evolutions of $E_{\text {corr }}$ and $E_{A C}$ recorded on samples Si3, Si11, Si14, and Si18 are similar to those of sample Si8 (Figure 3), the differences found being in the values of $E_{\text {corr }}$ and $\Delta_{E}$.

The values in Table 2 show that as the Si content of the samples increases (Table 1), the $E_{\text {corr }}$ values become more electronegative, and the $\Delta_{E}$ value decreases, which indicates that the corrosivity of the material decreases (passivity increases in AC polarization).

Table 2. $E_{c o r r}$ and $\Delta_{E}$ values recorded (100 minutes) for the investigated samples at $J_{a c}$ current densities $(50 \mathrm{~Hz} \mathrm{AC})$

\begin{tabular}{|c|c|c|c|c|c|c|c|c|c|c|}
\hline \multirow{3}{*}{$\begin{array}{c}J_{a c} \\
{\left[\mathrm{~A} / \mathrm{m}^{2}\right]}\end{array}$} & \multicolumn{10}{|c|}{ Samples } \\
\hline & \multicolumn{2}{|c|}{ Si3 (3 \%Si) } & \multicolumn{2}{|c|}{ Si8 (8 \%Si) } & \multicolumn{2}{|c|}{ Si11 (11 \%Si) } & \multicolumn{2}{|c|}{ Si14 (14 \%Si) } & \multicolumn{2}{|c|}{ Si18 (18 \%Si) } \\
\hline & $\begin{array}{c}E_{O P C}=E_{\text {corr }} \\
{\left[\mathrm{mV}_{\mathrm{SCE}}\right]}\end{array}$ & $\begin{array}{c}\Delta_{E} \\
{[\mathrm{mV}]}\end{array}$ & $\begin{array}{c}E_{\mathrm{OPC}}=E_{\text {corr }} \\
{\left[\mathrm{mV}_{\mathrm{SCE}}\right]}\end{array}$ & $\begin{array}{c}\Delta_{E} \\
{[\mathrm{mV}]}\end{array}$ & $\begin{array}{c}E_{O P C}=E_{\text {corr }} \\
{\left[\mathrm{mV}_{\mathrm{SCE}}\right]}\end{array}$ & $\begin{array}{c}\Delta_{E} \\
{[\mathrm{mV}]}\end{array}$ & $\begin{array}{c}E_{\mathrm{OPC}}=E_{\text {corr }} \\
{\left[\mathrm{mV}_{\mathrm{SCE}}\right]}\end{array}$ & \begin{tabular}{|c|}
$\Delta_{E}$ \\
{$[\mathrm{mV}]$}
\end{tabular} & $\begin{array}{c}E_{O P C}=E_{\text {corr }} \\
{\left[\mathrm{mV} V_{\text {SCE }}\right]}\end{array}$ & $\begin{array}{c}\Delta_{E} \\
{[\mathrm{mV}]}\end{array}$ \\
\hline 0 & -562 & 0 & -590 & 0 & -590 & 0 & -594 & 0 & -599 & 0 \\
\hline 0.1 & & 10 & & 5 & & 4 & & 3 & & 2 \\
\hline 1 & & 25 & & 20 & & 15 & & 7 & & 5 \\
\hline 10 & & 51 & & 35 & & 25 & & 16 & & 12 \\
\hline 80 & & 88 & & 63 & & 55 & & 45 & & 41 \\
\hline 300 & & 115 & & 81 & & 72 & & 63 & & 61 \\
\hline
\end{tabular}

Figure 5 shows the average mass losses recorded on the sample pairs after exposure for 240 hours to AC polarization vs. current density $\left(J_{a c}\right)$.

Figure 5 shows that for all samples investigated at a current density of up to $10 \mathrm{~A} / \mathrm{m}^{2}$, the mass losses are insignificant (below $0.2 \mathrm{~g}$, respectively, below $8.3 \times 10^{-5} \mathrm{~g} / \mathrm{Ah}$ ). At a current density of $100 \mathrm{~A} / \mathrm{m}^{2}$, for samples with a Si content higher than $8 \%$, the mass losses are less than $0.9 \mathrm{~g}$, respectively $3.75 \times 10^{-4} \mathrm{~g} / \mathrm{Ah}$ (about 150x less than in the case of similar, polarized materials in DC [31]). The results on the AC polarization behavior of silicone 
cast iron samples in $0.1 \mathrm{M} \mathrm{KCl}$ solution can be explained by Figure 4, which shows that the investigated electrochemical system responds to $A C$ polarization through an anodic global current, results that are consistent with those reported for the electrochemical behavior of similar materials [29].

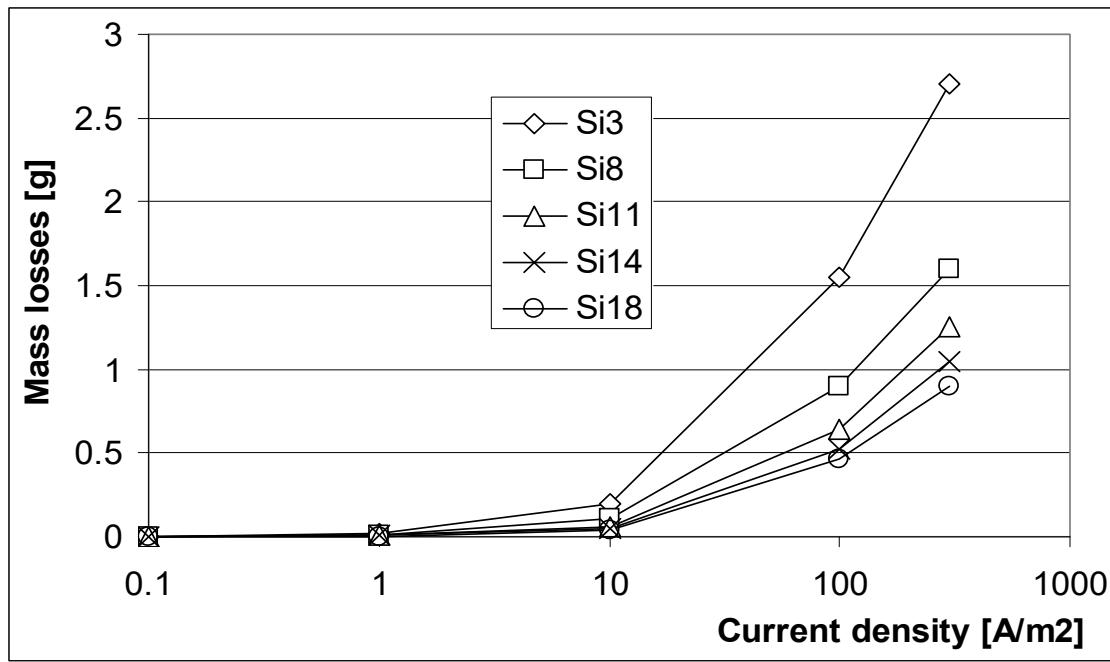

Figure 5. Mass losses vs. current density of the investigated samples.

Figure 6 illustrates the representative SEM images regarding the investigated samples' morphology, according to the Si content: 3\% Si, 8\% $\mathrm{Si}$, and $18 \% \mathrm{Si}$.

Comparative analysis of images a, b, c, and d in Figure 6, highlights as a common element the presence of graphite spherical precipitations, specific to silicon cast iron with silicon content higher than 3\% [33, 34]. The Si3 sample (Figure 6 a- approx. 3\% Si) presents a structure in which the two major crystalline structures (distributed relatively homogeneously) are distinguished, identified by XRD (Figure 1- $\mathrm{Fe}$ and $\mathrm{Fe}_{3} \mathrm{Si}$ cubically crystallized). The Si8 sample (Figure $6 \mathrm{~b}$ - $8 \% \mathrm{Si}$ ) shows a homogeneous structure, uniformly crystallized ( $\mathrm{Fe}_{3} \mathrm{Si}$ - according to Figure 2), which explains the unique mechanical characteristics reported [29]. The Si18 sample (Figure 6c, d$18 \% \mathrm{Si}$ ) shows a tense structure in which small crystals of $\mathrm{Fe}_{3} \mathrm{Si}$ prevail (Figure 2), and the presence of intercrystalline cracks is noticed (explains the high fragility reported [29]). 

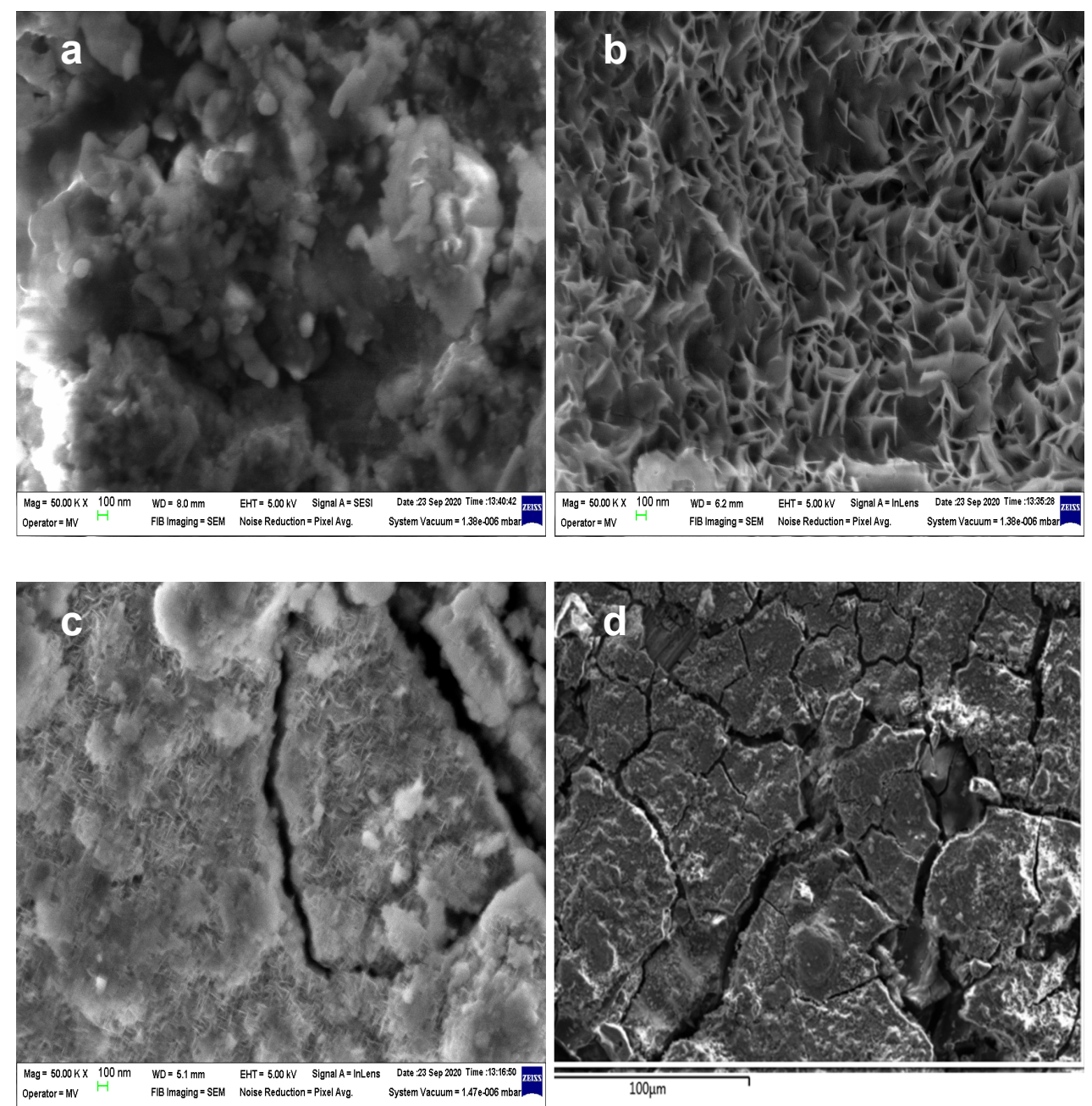

Figure 6. SEM images of the samples: a- $3 \% \mathrm{Si}, \mathbf{b}-8 \% \mathrm{Si}$, and $\mathbf{c}, \mathbf{d}-18 \% \mathrm{Si}$.

Table 3 summarizes the results of EDAX measurements (superficial elementary compositions- average values for 5 spectra recorded in 5 different locations) obtained on surface $A$ (unexposed to polarization in $A C$ ) compared to surface $B$ (exposed to polarization in $50 \mathrm{~Hz}, \mathrm{AC} 300 \mathrm{~A} / \mathrm{m}^{2}$, for 240 hours), normalized for the main elements identified $(100 \%$ specified components). 
The analysis of the data presented in Table 3 shows that, following the polarization of the investigated samples in $50 \mathrm{~Hz} \mathrm{AC}$ with $300 \mathrm{~A} / \mathrm{m}^{2}$, the oxygen content of the investigated surface layer (surface $B$ ) increases significantly as compared to that of the samples not exposed to AC polarization (surface A). The oxygen content of surfaces exposed to AC polarization decreases with increasing $\mathrm{Si}$ content of the investigated samples.

Table 3. The value of $50 \mathrm{~Hz}$ AC polarization $\left(240\right.$ hours at $\left.J_{a c} 300 \mathrm{~A} / \mathrm{m}^{2}\right)$ of the exposed $(B)$ and unexposed $(A)$ samples surface

\begin{tabular}{|c|c|c|c|c|c|c|c|c|c|c|}
\hline \multirow{2}{*}{ Elements } & \multicolumn{10}{c|}{ Sample- content Wt [\%] } \\
\cline { 2 - 11 } & \multicolumn{2}{|c|}{ Si3 } & \multicolumn{2}{c|}{ Si8 } & \multicolumn{2}{c|}{ Si11 } & \multicolumn{2}{c|}{ Si14 } & \multicolumn{2}{c|}{ Si18 } \\
\cline { 2 - 11 } & A & B & A & B & A & B & A & B & A & B \\
\hline $\mathbf{S i}$ & 3.4 & 3.38 & 8.82 & 8.92 & 11.25 & 11.26 & 14.31 & 14.43 & 17.27 & 17.28 \\
\hline $\mathbf{F e}$ & 94.1 & 63.40 & 87.95 & 61.88 & 86.39 & 63.36 & 82.01 & 62.79 & 79.66 & 61.77 \\
\hline $\mathbf{0}$ & 0.10 & 31.95 & 0.15 & 27.9 & 0.20 & 24.52 & 0.25 & 21.72 & 0.35 & 19.88 \\
\hline $\mathbf{C}$ & 1.26 & 1.27 & 1.29 & 1.30 & 0.85 & 0.86 & 1.05 & 1.06 & 1.05 & 1.07 \\
\hline $\mathbf{M n}$ & 0.41 & 0 & 0.75 & 0 & 0.64 & 0 & 0.98 & 0 & 0.52 & 0 \\
\hline $\mathbf{C r}$ & 0.13 & 0 & 0.51 & 0 & 0.51 & 0 & 0.83 & 0 & 0.22 & 0 \\
\hline $\mathbf{C u}$ & 0.6 & 0 & 0.53 & 0 & 0.16 & 0 & 0.57 & 0 & 0.93 & 0 \\
\hline
\end{tabular}

Also, during polarization in $\mathrm{AC}$, the metallic elements $\mathrm{Mn}, \mathrm{Cr}$, and $\mathrm{Cu}$ are entirely dissolved from the samples' surface. These findings, in context with Figure 4, suggest that the main processes that occur in AC polarization of silicone cast iron in aqueous media consist of anodic oxidation of iron with the formation of iron oxide films (3):

$$
x \mathrm{Fe}+2 \mathrm{yOH}^{-} \rightarrow \mathrm{Fe}_{x} \mathrm{O}_{y}+y \mathrm{H}_{2} \mathrm{O}+2 y e^{-},
$$

and the anodic dissolution of some metals $\mathrm{Me}$ from the composition of silicon cast irons (such as $\mathrm{Mn}, \mathrm{Cr}, \mathrm{Cu}$ ), with the formation of soluble compounds (4):

$$
M e \rightarrow M e^{z+}+z e^{-},
$$

where $\mathrm{z}^{+}$represents the valence of the dissolved metal, and $\mathrm{e}^{-}$the elementary charge (electron) released.

The anodic processes (3) and (4) are coupled with the cathodic processprobably to reduce the dissolved oxygen in the solution, respectively (5):

$$
\mathrm{O}_{2} \rightarrow 2 \mathrm{O} ; \mathrm{O}+2 \mathrm{e}^{-} \rightarrow \mathrm{O}^{2-} ; \mathrm{H}_{2} \mathrm{O}+\mathrm{O}^{2-} \rightarrow 2 \mathrm{OH}^{-}
$$

Experimental results indicate that silicon cast irons with $\mathrm{Si}$ content above $8 \%$ present high stability to AC polarization. Thus, such materials can be used successfully to achieve long-lasting (life over 100 years) earthing plats for power systems [17-19], durable electrodes for the protection of the 
underground gas pipelines exposed to AC stray currents [19], inert electrodes for the electrochemical processes, including bioelectrochemical technologies (stimulation of biological processes for wastewater treatment [28], acceleration and control of fermentation processes to obtain biogas [26]). When used as inert electrodes in electrochemical processes, it is necessary to consider the effects of electrolyte impurity with metal ions found in the composition of silicon cast iron used ( $\mathrm{Fe}, \mathrm{Cr}, \mathrm{Cu}$, and $\mathrm{Mn})$.

\section{CONCLUSIONS}

Through electrochemical, gravimetric, XRD, and SEM-EDAX investigations, silicone cast irons with silicon content between 3 and 18\% were characterized. Analysis of the obtained experimental data shows that:

-in the microstructure of the investigated samples, for the samples with $\mathrm{Si}$ content of approximately $3 \%, \mathrm{Fe}$ and $\mathrm{Fe}_{3} \mathrm{Si}$ crystals prevail, unlike samples with Si content higher than $8 \%$, in which XRD highlighted only cubically crystallized $\mathrm{Fe}_{3} \mathrm{Si}$;

-the Si content of the samples determines the electronegativity (the open circuit potential- $\left.E_{\text {corr }}\right)$ of the investigated samples, immersed in $0.1 \mathrm{M}$ $\mathrm{KCl}$ solution (between $-562 \mathrm{mV}_{\mathrm{SCE}}$ for Si3 and $-599 \mathrm{mV} \mathrm{SCE}_{\mathrm{SO}}$ for Si18), and increases with the Si content of the sample;

-at the AC polarization of the investigated samples, their potential becomes more electropositive than $E_{\text {corr }}$, the migration to more electropositive values of $\Delta_{E}$ is determined by the density $J_{a c}$ of the polarization current (increases with increasing $J_{a c}$ ) and by the $\mathrm{Si}$ content of the samples (increases with decrease in Si content);

-mass losses at AC polarization are determined by $J_{a c}$ (increases with increasing $J_{a c}$ ) and the $\mathrm{Si}$ content of the samples (increases with decreasing Si content); at $J_{a c}$, less than $10 \mathrm{~A} / \mathrm{m}^{2}$, the losses are insignificant (below $8.5 \times 10^{-5} \mathrm{~g} / \mathrm{Ah}$ ) for all samples, and at $J_{a c} 100 \mathrm{~A} / \mathrm{m}^{2}$, samples with Si content higher than $8 \%$, below $3.75 \times 10^{-4} \mathrm{~g} / \mathrm{Ah}$ (approx. 150x less than in the case of similar anodized polarized materials in DC);

-the main processes that occur in AC polarization of silicon cast irons in aqueous media consist of the anodic oxidation of iron with the formation of iron oxide films and the anodic dissolution with the formation of soluble compounds of some metals from the composition of silicon cast irons $(\mathrm{Mn}$, $\mathrm{Cr}, \mathrm{Cu}$ ), probably coupled with the cathodic process of reducing dissolved oxygen in solution.

Based on these findings, silicone cast irons with $\mathrm{Si}$ content higher than $8 \%$ present high stability to AC polarization and can be successfully used to achieve long-lasting earthing plats for power systems, protective electrodes for 
underground gas pipelines exposed to AC stray currents, inert electrodes with applications in electrochemical and bioelectrochemical technologies (stimulation, acceleration, and control of biological processes with industrial applications).

\section{EXPERIMENTAL SECTION}

Samples of high-silicon cast irons were obtained by usual metallurgical techniques from steel scraps and metallurgical silicon (ferrosilicon). After casting, the samples were sandblasted with sand, washed, and dried in an oven at $90 \pm 50^{\circ} \mathrm{C}$, preceding the experimental determinations. The elemental analysis of the obtained alloys was performed through optical emission spectrometry technique, with a specialized equipment type LAVWA $18 \mathrm{~A}$ from SPECTRO Analytical.

XRD and SEM-EDAX techniques were employed in the morpho-structural analysis of the obtained high-silicon cast iron samples. XRD measurements were performed with D8 Discover equipment (from Bruker), configured on primary optics with a Cu tube with primary radiation $(\lambda=1.540598 \AA)$, Göebel mirror, and on secondary optics with a 1D LynxEye detector. SEM-EDAX measurements were performed using an energy dispersive X-ray spectrometer (EDS), INCA Energy 250, Oxford Instruments, combined with Zeiss field emission scanning electron microscope (FESEM).

In a parallelepiped vessel, two samples (approx. 100x100 mm with a thickness of approx. $5 \mathrm{~mm}$ ) were fixed in a parallel plane position (distance between samples approximately $16 \mathrm{~cm}$ ) and immersed in $0.1 \mathrm{M} \mathrm{KCl}$ solution. The samples were connected to the output of a $50 \mathrm{~Hz}$ power supply with an adjustable voltage between 1 and $20 \mathrm{~V}$, thus ensuring polarizations in $A C$ at $J_{a c}$ between 1 and $300 \mathrm{~A} / \mathrm{m}^{2}$. Time evolution of the potentials in the open circuit $\left(E_{c o r r}\right.$ at $\left.J_{a c}=0\right)$ and the evolution of the $E_{A C}$ polarization potential in 50 $\mathrm{Hz} \mathrm{AC}$ were determined at $J_{a c}$ current densities between 1 and $300 \mathrm{~A} / \mathrm{m}^{2}$, against a saturated calomel electrode (SCE) with a PM2517E type multimeter manufactured by Philips (input impedance higher than $10 \mathrm{M} \Omega$ ).

Sample mass losses were calculated by measuring the samples before and after AC polarization (at various $J_{a c}$ for 240 hours). Measurements were performed with a digital analytical scale with an accuracy of $\pm 0.0001 \mathrm{~g}$ (type Precisa 320 XR -model XR125SM from Precisa Gravimetrics AG). For each sample, measurements were performed on the surface unexposed to polarization in $\mathrm{AC}$ compared to the surface exposed to polarization in $50 \mathrm{~Hz}$ $\mathrm{AC}\left(240\right.$ hours at $300 \mathrm{~A} / \mathrm{m}^{2}$, in $0.1 \mathrm{M} \mathrm{KCl}$ solution). 
CSABA BARTHA, VIRGIL MARINESCU, MONICA JIPA, BEATRICE-G. SBARCEA, ATTILA TÓKOS, ALINA-R. CARAMITU, IOSIF LINGVAY

\section{ACKNOWLEDGMENTS}

This work was financially supported by a grant of the Romanian Ministry of Education and Research, CCCDI - UEFISCDI, under the scientific Programme PN III - PTE, Contract 12 PTE/2020- ESELFBio.

\section{REFERENCES}

1. A. Świercz; E. Zajęcka; Carpathian J. Earth Environ. Sci., 2018, 13 (1), 249-266.

2. G.M. Ispas; C. Roba; R. Bâlc; D.M. Gligor; Carpathian J. Earth Environ. Sci., 2020, 15 (2), 415-428.

3. M.R. Niță; C.I. Ioja; Carpathian J. Earth Environ. Sci., 2020, 15 (2), 471-479.

4. E.A. Stere; I. Popa; Electroteh. Electron. Autom., 2018, 66 (4), 127-134.

5. T. Erdey-Grúz; Kinetics of electrode processes, Akadémiai kiadó, Budapest, Hungary, 1969, pp. 15-45.

6. Y. Xianjin; Z. Lipeng; D. Yunhui; Z. Zengdian; J. Rare Earths, 2006, 24 (1), 352354.

7. F. Zaza; C. Paoletti; R. Lo-Presti; E. Simonetti; M. Pasquali; J. Power Sources, 2010, 195 (13), 4043-4050.

8. R.D. Xu; L.P. Huang; J.F. Zhou; P. Zhan; Y.Y. Guan; Y. Kong; Hydrometallurgy, 2012, 125-126, 8-15.

9. W. Yun-Hai; C. Qing-Yun; L. Guo; L. Xiang-Lin; Anodic materials with high energy efficiency for electrochemical oxidation of toxic organics in waste water, in: Industrial waste, K. Y. Show, X. Guo Eds; IntechOpen, Rijeka, Croatia, 2012, Chapter 2, pp. 33-50

10. I. Gallino; M.E. Kassner; R. Busch; Corros. Sci., 2012, 63, 293-303.

11. D. Jia; K. Wang; J. Huang; Chem. Eng. J., 2017, 317, 673-686.

12. H. Chu; Q. Wu; J. Huang; Colloids Surf. A Physicochem. Eng. Asp., 2018, 558, 495-503.

13. S. Permeh; K. Lau; M.E. Boan; B. Tansel; M. Duncan; J. Mater. Civ. Eng., 2020, 32 (7), 04020184.

14. O.G. Kuznetsova; A.M. Levin; O.I. Tsybin; M.A. Sevostyanov; V.A. Bryukvin; A.O. Bolshikh; Russ. Metall., 2018, 2018 (7), 651-654.

15. K.V. Hansen; M. Chen; T. Jacobsen; K.T.S. Thydén; S.B. Simonsen; S. Koch; M.B. Mogensen; J. Electrochem. Soc., 2016, 163 (10), 1217- 1227.

16. S. Geißler; H. Tiainen; H.J. Haugen; Mater. Sci. Eng. C., 2016, 63, 359-366.

17. I. Lingvay; C. Homan; C. Lingvay; Rev. Chim., 2007, 58 (11), 1051-1054.

18. I. Lingvay; A. Voina; C. Lingvay; C. Mateescu; Rev. Roum. Sci. Techn.Électrotechn. Énerg, 2008, 53 (2), 95-112.

19. I. Lingvay; A.M. Bors; D. Lingvay; L. Radermacher; V. Neagu; Rev. Chim., 2018, 69 (12), 3593-3599.

20. D. Sandu; I. Lingvay; S. Lányi; D.D. Micu; C.L. Popescu; J. Brem; L.C. Bencze; C. Paizs; Studia UBB Chemia, 2009, 54 (4), 195-201. 
21. R.W. Hunt; A. Zavalin; A. Bhatnagar; S. Chinnasamy; K.C. Das; Int. J. Mol. Sci., 2009, 10, 4515-4558.

22. M. Gao; J. Zhang; H. Fen; Bioelectromagnetics, 2011, 32, 73-78.

23. C. Stancu; M. Lingvay; I. Szatmári; I. Lingvay; The $8^{\text {th }}$ Int. Symp.on ATEE, Bucharest, Romania, May 23-25, 2013, 1-4.

24. E. Radu; D. Lipcinski; N. Tănase; I. Lingvay; Electroteh. Electron. Autom., 2015, 63 (3), 68-74.

25. M. Lingvay; A.R. Caramitu; A.M. Bors; I. Lingvay; Studia UBB Chemia, 2019, 64 (2), 279-288.

26. C. Mateescu; I. Lingvay; A. Caramitu; N. Tanase; E. Radu, RO Patent RO132199 B1, 2020.

27. C. Bartha; A. Caramitu; M. Jipa; D.M. Ignat; A. Tókos; Studia UBB Chemia, 2020, 65 (4), 85-93.

28. C. Bartha; M. Jipa; A.R. Caramitu; A. Voina; A. Tókos; D.M. Ignat; I. Lingvay; Rev. Roum. Sci. Techn.- Électrotechn. Énerg, 2020, in press

29. M. Stawarz; W. Kajzer; A. Kajzer; M. Dojka; Arch. Foundry Eng., 2017, 17 (2), 101-106.

30. U. de la Torre; A. Loizaga; J. Lacaze; J. Sertucha; J. Mater. Sci. Technol., 2014, 30 (12), 1425-1431.

31. Specialist Castings Limited; High Silicon Cast Iron Anode, (n.d.).

32. I. Lingvay; C. Lingvay; G. Rus; I. Laţa; V. Pavlovschi; L. Ancas; RO Patent 120717 B1, 2001.

33. R. González-Martínez; U. de la Torre; J. Lacaze; J. Sertucha; Mater. Sci. Eng. A, 2018, 712, 794- 802.

34. P. Rubin; R. Larker; E. Navara; M.L. Antti; Metallogr. Microstruct. Anal., 2018, 7, 587-595. 